1. Uma revisão da literatura;

2. O conceito de tecnologia;

3. A estratégia da pesquisa;

4. A formulação de hipóteses;

5. Comentários finais.

* O presente artigo foi apresentado ao Seminário sobre Organização e Ambiente, organizado pelo Departamento de Administração Geral e Recursos Humanos da EAESP/FGV em agosto de 1975. Ele se baseia nos capítulos 1 e 2 da tese de doutorado do autor: Technology and organization structure: a comparative case-study of automotive and processing firms in Brazil. Cornell University, Ithaca, New York, 1975.

A tese será publicada brevemente sobre o mesmo título, pelo

Latin American Program Studies da Cornell University.

** Professor visitante, Programa de Pós-Graduação da Faculdade de Economia e Administração. Universidade Federal de Minas Gerais. Ex-professor da Escola de Administração de Empresas da Fundação Getulio Vargas.
A finalidade deste artigo é demonstrar a metodológia utilizada ao pesquisar a possibilidade de ver a tecnologia como uma variável indicativa de estrutura organizacional. Um primeiro passo nessa direção compreende a revisão completa da evidência teórica e empírica realmente disponível nesse assunto. A identificação do conceito particular de tecnologia a ser selecionado neste estudo, bem como as maneiras pelas quais este conceito poderia ser operacionalizado, são pontos a serem desenvolvidos mais tarde. A intenção final é a de formular hipóteses para pesquisa empírica que-envolvam a correlação de ambas as variáveis, isto é, tecnologia e estrutura organizacional.

\section{UMA REVISÃO DA LITERATURA}

Para efeito desta revisão, o conceito de tecnologia será considerado como sendo não-dimensional e ficará temporariamente sem definição. $O$ conceito de estrutura organizacional, por sua vez, será dividido em duas dimensões: estrutura de tarefas e estrutura social. A estrutura de tarefas é geralmente definida como a distribuição oficial de atividades intencionalmente prescritas para se alcançar um objetivo geral. Elementos nessa dimensão são, por exemplo, hierarquia e funcionalização. Estrutura social, por sua vez, diz respeito às relações interpessoais bem como os valores, idéias e regras que as governam, as quais acompanham as atividades formalizadas pela estrutura de tarefas. ${ }^{1}$

\subsection{Tecnologia e estrutura de tarefas}

Embora o impacto da tecnologia sobre a estrutura de tarefas tenha sido muito pesquisado empiricamente através de estudos de correlação, tais assuntos foram estimulados por um trabalho estritamente teórico. A proposição geral desenvolvida por Thompson e Bates" de que "... o tipo de tecnologia disponivel e conveniente para tipos particulares de objetivos organizacionais estabelece limites nos tipos de estruturas apropriadas para as organizações" foi baseada numa comparação totalmente simulada entre organizações tão diversas quanto uma fábrica, uma mina, um hospital e uma universidade. Suas especulações levaram-nos adiante para formular hipóteses sobre os diferentes tipos de automatização como sendo determinantes de mecanismos pessoais e impessoais de controle existentes na organização. Do mesmo modo, um estudo teórico, tal como o sistema de classificação de organizações por padrões técnicos, isto é, rotineiros, não-rotineiros, etc., construído por Perrow, ${ }^{3}$ é digno de ser mencionado também como ponto de referência para muitos outros pesquisadores. Para cada padrão técnico, Perrow formula como hipótese um número de relacionamento entre a tecnologia e as características da estrutura de tarefas (medida em termos de "rotina individual") e entre estas características e as inter-relaçōes existentes ao nível de grupo. Assim, por exemplo, um alto nível de rotina indi-

16 (2): 7-16,

mar./abr. 1976 
vidual seria associado a um alto poder do grupo "técnico" (staff) sobre o grupo "de supervisão" (linha), à coordenação intergrupal baseada em planejamento e a um baixo nivel de interdependência dos grupos mencionados.

Embora reivindicando serem aplicáveis a todas organizaçðes, algumas das hipóteses de Perrow foram reconhecidamente confirmadas apenas por Magnusem ${ }^{4}$ num estudo abrangendo 14 corporações manufatureiras de tamanho médio nos Estados Unidos:

"Examinando as percepções gerenciais sobre a rotina de seus trabalhos, uma certa tecnologia modal foi determinada para cada uma das organizações e usada para classificá-las nos quadrantes do modelo tecnológico-organizacional de Perrow; quando isso foi feito, no entanto, os dados mostraram que as companhias pareciam ser mais homogêneas do que fora previsto e podiam ser categorizadas apenas em rotineiras e não-rotineiras. Os modelos de artesanato e engenharia foram conseqüentemente eliminados da análise.

A despeito dessa redução de alcance teórico, as diferenças entre as organizaçōes rotineiras e não-rotineiras, no que se refere a estrutura de tarefas, seguiram as direções prognosticadas pela teoria de Perrow."

Que as organizações podem ser distribuídas em um contínuo mecanístico-orgânico de acordo com um critério tecnológico; no entanto, não é uma nova idéia.

Anos antes que o trabalho de Perrow fosse publicado, Burns e Stalker ${ }^{5}$ já tinham informado sobre os relacionamentos existentes entre tecnologia, estrutura de tarefas e nível de desempenho, baseados numa pesquisa feita em 20 firmas escocesas. Para eles, uma estrutura organizacional "flexível" pareceu ser apropriada para um ambiente tecnológico em mudança e uma estrutura organizacional mais "rígida" para um ambiente tecnológico estável. Além disso, diferenças estruturais entre as organizações foram também relacionadas com diferenças normativas e comportamentais.

Outros pesquisadores ${ }^{6}$ chegaram recentemente a conclusões similares às mencionadas. De grande relevância é o trabalho da socióloga inglesa Joan Woodward. ${ }^{7}$

$\mathrm{Na}$ pesquisa feita por Woodward em 100 firmas manufatureiras na área do sul do condado de Essex, na Inglaterra, a maioria das diferenças organizacionais detectadas não foram inicialmente explicadas por tais fatores como tamanho da companhia, tipo de indústria ou personalidade do executivo de maior nivel. Por outro lado, o grau de conformidade demonstrado com relação aos princípios clássicos de organização não mostrou nenhum relacionamento com o sucesso econômico-financeiro das firmas estudadas.

Foi só depois de as firmas se tornarem classificadas numa escala de "complexidade técnica" composta de três categorias maiores (produção por unidade, produção em grande escala e produção de processo contínuo) que os dados coletados sobre as estruturas de tarefas e os padrões gerenciais começaram a fazer sentido. Medidas de configuração organizacional apresentaram um relacionamento linear (isto é, comprimento da linha de comando, etc.) ou curvilinear (por exemplo: desenvolvimento da organização linha/staff, etc.) com o grau de "complexidade" da tecnologia. Finalmente, quanto mais estes relacionamentos aproximavam-se à média correspondente à categoria industrial, maior parecia ser o sucesso econômico da firma.

Assim, o trabalho de Woodward poderia ser resumido em três hipóteses. Uma primeira pressupõe a existência de um "imperativo tecnológico" agindo sobre a variável de estrutura de tarefas em organizações num modo relativamente sistemático. Desta forma, as organizações parecem adotar uma estrutura consistente com os "requisitos" de sua tecnologia. Uma segunda hipótese sugeriria que as organizações centralizadas em sistemas de produção localizados em extremos de uma escala descritiva de "complexidade tecnológica" podem mais provavelmente apresentar um caráter orgânico do que as localizadas no meio da mesma escala. Finalmente, uma terceira hipótese apoiaria um relacionamento entre tecnologia, estrutura de tarefas e desempenho econômico-financeiro.

Surpreendentemente, exceto pelo estudo correlacional de Fullan ${ }^{8}$ de 12 firmas pertencentes aos ramos automobilístico e de processamento de petróleo no Canadá, as hipóteses de Woodward não têm sido consistentemente confirmadas por estudos mais recentes sobre $o$ assunto. Embora parte desta inconsistência possa ser creditada nas diferenças relativas a definições de conceitós e metodologia, uma revisão breve das descobertas destes esforços de pesquisa pode ser interessante em si mesma.

Mohor, ${ }^{9}$ por exemplo, descobriu a tecnologia (operacionalizada em termos do critério de Perrow de "rotina individual") como não sendo determinante da estrutura de tarefas em 13 departamentos de previdência social. Similarmente, Sammuels e Mannheim ${ }^{10}$ não acharam nenhum relacionamento significativo entre tipo de produção (unidade, massa, processo contínuo) e intensidade de controle estrutural (exemplo, comprimento da linha de comando, extensão de controle dos diversos níveis hierárquicos) numa pesquisa de 30 empresas em Israel. Esses autores também não crêem que a tecnologia esteja significativamente relacionada com as variáveis de formalização, funcionalização e impessoalidade na direção curvilinear prognosticada por Woodward.

Aparentemente o desafio mais sério às descobertas de Woodward foi apresentado por uma equipe de pesquisadores pertencentes a Universidade de Aston em Birmingham, Inglaterra. ${ }^{11}$ Baseado num estudo de 31 organizações manufatureiras, este grupo relatou uma surpreendente falta de associação entre "integração de fluxo de trabalho" (sua própria medida de "complexidade" tecnológica) e certas dimensões de estrutura organizacional, tais como as de estruturação de atividades, concentração de autoridade e outras. Pior ainda, nem as relações lineares, nem muitas das relações curvilineas existentes entre tecnologia e configuração organizacional descobertas por Woodward nas empresas do condado de Essex parecem ser verdadeiras para as organizações de Birmingham. No entanto, o Grupo Aston tem explicado razoavelmente tais discrepâncias formulando a hipótese de que: 
"Variáveis estruturais são associadas com a tecnologia de operações somente onde elas estão focalizadas no fluxo de trabalho. Quanto menor a organização, tanto mais sua estrutura será influenciada por tais efeitos tecnológicos; quanto maior a organização, tanto mais estes efeitos serão confinados a variáveis menores tais como o número de empregados em atividades ligadas com o próprio fluxo de trabalho, e não serão detectados em variáveis da mais remota incidência sobre estrutura administrativa e hierárquica."12

Para o Grupo de Aston, então, tamanho e tecnologia de uma organização são variáveis relacionadas por definição.

\subsection{Tecnologia e estrutura social}

Não obstante algumas questões não permaneçam ainda claras, os comentários precedentes sugerem que parece haver definitivamente um relacionamento entre a tecnologia e a estrutura de tarefas de uma organização. Isto significa que é razoável esperar diferenças sistemáticas na estrutura de tarefas das organizações. Se tais diferenças estão, na verdade, relacionadas a diferenças em valores ou formas de comportamento organizacional, é uma outra questão.

Pesquisa relativa ao impacto da tecnologia sobre a estrutura social do indivíduo e do grupo tem suas raízes na escola de relaçōes humanas. Embora negligenciada pelos seguidores de Mayo, no primeiro estágio desta escola, a variável tecnológica pareceu desempenhar um papel central no livro $O$ sistema social da fábrica moderna de W. L. Warner. ${ }^{13}$ Embora neste livro o autor aceite e use a abordagem básica desenvolvida em Hawthorne, ele leva a análise a um passo adiante. Como relatado por Mouzelis: 14 "Ele (Warner) está não só satisfeito de ver como as variáveis organizacionais entram na situação do indivíduo, mas também tenta examinar esses fatores ambientais em si nesmos. Por exemplo, Warner mostra como uma interrupç̃̃o na hiorarquia de oportunidades tem um impacto no status do trabalhador e na sua definição da situação - tudo isto levando a uma greve. Warner continua explicando esta mudança no status através de um exame sistemático das mudanças na tecnologia, no tamanho dos mercados e das firmas e no seu impacto na comunidade e assim por diante. Deste modo, ele fornoce um modelo mais completo dos mecanismos de mudança."

Depois de Warner vieram os interacionistas. Sua abordagem, primeiro elaborada por Chapple ${ }^{15}$ e Aresberg ${ }^{16}$ na Universidade de Harvard, e continunda logo em seguida por Whyte ${ }^{17}$ e Sayles, ${ }^{18}$ advogava a observação e medição do comportamento dos membros do grupo. Segundo eles, uma vez que tais medidas sejam executadaş, o papel determinante da estrutura técnica e de processo nos padrōes de interação interpessoal torna-se evidente. A seqüência, freqüência e duração das interaçōes sociais dependem em grande parte do fluxo de trabalho, isto é, da maneira em que os materiais são processados de um posto de trabalho para o outro durante um certo periodo de tempo. As relações humanas na indústria de restaurante, de Whyte, é um exemplo clássico desta linha de pensamento.

As pesquisas sobre liderança conduzida em organizações ${ }^{19}$ também sugerem que o comportamento do pessoal de supervisão é afetado por fatores técnicos tais como a variabilidade das operações supervisionadas. Dubin 20 acredita, que a consideração, por parte dos supervisores, dos trabalhadores como indivíduos decai quando a tecnologia se torna mais complexa e o horário de produção mais exigente. Burak ${ }^{21}$ também prediz um ligeiro aumento de "proximidade de supervisão" como uma conseqüência de maiores reajustamentos no ritmo de trabalho derivados de condições tecnológicas mais adiantadas. Finalmente, Fiedler ${ }^{22}$ achou um relacionamento entre certas condições de liderança, (grau de estrutura da tarefa, relações pessoais entre o supervisor e os subordinados e poder do supervisor) e desempenho eficiente. Sob ambas as condições de liderança, extremamente favorável e extremamente desfavorável, um estilo de liderança autoritária parece estar relacionado ao desempenho mais eficiente da tarefa do grupo. Em condiçōes de liderança intermediárias, por sua vez, é um comportamento mais permissível o que parece estar associado a um desempenho mais eficiente.

Uma abordagem mais direta ao relacionamento entre a tecnologia e a estrutura social, ao nível do grupo, foi desenvolvida por Trist e Banforth. ${ }^{23}$ Baseados no estudo do método long-wall de mineração utilizado nas minas de carvão na Inglaterra, estes autores concluíram que toda organização desenvolve propriedades sociais e psicológicas, as quais não dependem necessariamente da tecnologia. No entanto, a integração dos papéis individuais diferenciados do grupo num todo social não pressupõe integração dos componentes do trabalho num "todo tecnológico". O fracasso em se obter um equilibtio entre os "interesses" sociais e técricos sempre presentes dentro do sistema organizacional provocaria conseqüências indesejáveis, tais corno-tenstes por parte da supervisão e exercício de táticas de defesa de grupo.

Embora reforindo-se a uma certa "organização" $\mathrm{em}$ abstrato, o conceito do "sistema sociotécnico" formulado por Trist e Banforth foi baseado na observação de grupos de trabalho. Foi portanto deixada para os outros pesquisadores a tarefa de estudar empiricamente a aplicação do conceito, ao nivel da estrutura social da organizagío como um todo. Isto foi desenvolvido principalmente através de estudos de casos. Entre eles, os mais dignos de nota são o contraste de organizaçðes subterrâneas e de superfície numa mina de gesso estudade por Gouldner, ${ }^{24}$ e a andlise intensiva de firmas individuais na amostra de empresas do condado de Essex feita por Woodward.

Entre outras coisas, o levantamento geral de empresas feito por Woodward mostrou que características organizacionais tais como linhas de comunicação, tensð̃es psicológicas e padrões de ínfluência interorganizacional não são independentes da tecnologia em uso. Esta conclusão preliminar foi confirmada mais tarde por Woodward num 
estudo de casos extraídos da amostra original. Aqui Woodward ${ }^{25}$ achou que a importância relativa dos diferentes grupos funcionais e seus relacionamentos variaram dentro de cada tipo de sistema de produção. Pesquisa e desenvolvimento predominando em firmas de produção por unidade, produção em firmas de produção em alta escala, e mercadologia em firmas de produção de processamento. Assim, para cada tipo de tecnologia corresponderia o predomínio de uma "função critica" especifica, a qual as firmas acima da média em sucesso pareceram recompensar adequadamente por meio dos seus sistemas de status.

Descobertas semelhantes relativas a tecnologia e influência interorganizacional foram comentadas mais recentemente por Lawrence e Lorsch. ${ }^{26}$ Eles examinaram o relacionamento entre organização e ambiente. De acordo com estes autores, o grau de diferenciação interfuncional dentro de cada organização parece variar em relação proporcional à incerteza do seu ambiente e, conseqüentemente, à maior ou menor "complexidade" da tecnologia existente. A integração, por sua vez, acaba sendo melhor servida quando a maioria das unidades funcionais reconhece a liderança de uma outra em cada ambiente. Como relatado por Magnusen: ${ }^{27}$ "onde o serviço de rotina era crítico (recipiente), requisitou-se uma integração mais firme entre produção e vendas (para cumprir como o programa de produção). Onde a inovação era mais importante (plásticos e processamento de alimentos), a interdependência teve que ser maior entre vendas e pesquisa e desenvolvimento e entre pesquisa e desenvolvimento e producão (para lidar com novos produtos e mudanças tecnológicas).

\subsection{Uma conclusão preliminar}

A revisão anterior das pesquisas empíricas feitas sobre o relacionamento entre tecnologia e estrutura organizacional pode ter sido sugestiva, embora dificilmente conclusiva. Tecnologia e estrutura organizacional parecem ser relacionadas entre si. As organizações acomodam-se a arranjos tecnológicos por meio da adoção de certas estruturas de tarefas e sociais. As formas apresentadas por estas estruturas, no entanto, são extremamente variadas. Através dos trabalhos revistos é dificil chegar a um sistema geral de classificação considerando tipos específicos de arranjos tecnológicos vis-à-vis estruturas organizacionais típicas.

Uma explicação desta situação pode residir no fato de que o conceito de tecnologia foi deliberadamente deixado sem definição no começo deste artigo. Isto ocorreu porque pareceu necessário demonstrar, primeiro, que o relacionamento entre tecnologia e estrutura organizacional está razoavelmente apoiado por descobertas empíricas. Visto que tal objetivo já foi atingido, parece apropriado neste ponto concentrar-se numa definição do conceito de tecnologia e num exame dos critérios por meio dos quais este conceito tem sido operacionalizado. Uma tentativa nesta direção será a matéria da próxima seção.

\section{O CONCEITO DE TECNOLOGIA}

A tarefa de definir o conceito de tecnologia será realizada em duas etapas. Primeiro, far-se-á menção à variedade de maneiras em que tal conceito aparece definido na literatura. Uma segunda etapa consistirá em rever os diferentes critérios por meio dos quais ele aparece operacionalizado na pesquisa empírica. Finalmente, uma justificação será adiantada sobre a abordagem que será tomada neste artigo quanto a essa matéria.

\subsection{Definição do conceito}

Definições gerais de tecnologia foram enunciadas por Blauner, ${ }^{28}$ Perrow, ${ }^{29}$ e mais recentemente por Fullan. ${ }^{30}$ Para usar a definição de Perrow como exemplo: "Entende-se por tecnologia as ações que um indivíduo executa em um objeto, com ou sem os recursos de ferramentas ou dispositivos mecânicos, para fazer alguma mudança naquele objeto. $\mathrm{O}$ objeto ou matéria-prima pode ser humano, vivo ou não, ou então um símbolo ou objeto inanimado."

A definição de Perrow é a mais completa em comparação com outras fornecidas pela literatura especializada. Isto é apoiado pelo fato de que ela concebe as ações executadas pelo indivíduo como sendo eventualmente independentes do uso de ferramentas ou "dispositivos mecânicos", bem como focalizadas num "objeto" amplamente definido. De acordo com Hickson e associados, tal definição abrangeria todas as perspectivas das quais a tecnologia pode ser observada em abstrato. Estas perspectivas são as de tecnologia de operações, tecnologia de conhecimentos e tecnologia de materiais.

O conceito de tecnologia de operações refere-se à expressão física adotada pelo núcleo produtivo de uma organização industrial. Como tal, este conceito se refere a ferramentas, instrumentos, máquinas e fórmulas técnicas essenciais para o desempenho do trabalho. ${ }^{31}$ Num sentido amplo, ela se refere aos equipamentos e à sequiência das atividades que compõem o fluxo de trabalho de um sistema de produção.

Supõe-se, no entanto, que há também uma razão para a existência de uma máquina, um processo, ou um método de produção. Assim, a tecnologia cobriria também o corpo de idéias expressando as finalidades do trabalho, sua importância funcional e a lógica dos métodos aplicados. ${ }^{32}$ Tal corpo de idéias constitui a tecnologia de conhecimentos, a qual é absorvida pelo individuo como conseqüência da incerteza que ele percebe como existente em seu ambiente de trabalho. Tecnologia de conhecimentos é assim concebida por Perrow ${ }^{33}$ como: ". . . uma reação individual ao número de casos excepcionais encontrados no trabalho e à medida que estes são percebidos como familiares ou não-familiares.

Característica a essa reação é a natureza do processo de busca empreendido quando as exceções ocorrem".

Mas, de onde vêm as fontes de incerteza? Para Perrow e outros, a incerteza é sempre inerente à natureza 
das matérias-primas. A estabilidade e a variabilidade de tais matérias-primas, bem como a sua compreensão, determinaria o processo de busca e, fundamentalmente, o tipo de tecnologia a ser usado. Portanto, rigorosamente definido, tecnologia de materiais consiste em: “. . uma variedade de técnicas, cuja seleção, combinação e ordem de aplicação são determinadas pelo feedback do próprio objeto (ou matéria-prima)". ${ }^{34}$

De todas as três dimensões de tecnologia comentadas previamente, a que melhor combina com os propósitos deste estudo é a de tecnologia de operações. Esta é não só observável por definição, mas parece condicionar as outras duas dimensões restantes, isto é, tecnologia de materiais e tecnologia de conhecimentos.

\subsection{Operacionalização do conceito}

Tentativas de desenvolvimento de medidas para identificar a tecnologia de operações diferem em termos de nível de análise (indivíduo, grupo, organização) e critérios de operacionalização (repetição, automação, complexidade, etc.).

Amplas regras teóricas sobre o assunto foram proporcionadas por March e Simon ${ }^{35}$ e Perrow. ${ }^{36}$ Para March e Simon, critérios indicadores de tecnologia são os de "repetição", "programação" e "previsibilidade" das atividades individuais. Preocupado mais com a descoberta de um critério inclusivo de tecnologia do que com questões de operacionalização, Perrow prefere lidar com variáveis abstratas tais como "número das exceções" e o grau de "analisabilidade dos problemas" encontrados pelo indivíduo no trabalho. Correlacionando ambas variáveis, um contínuo abstrato de "rotina individual" emerge ordenando as organizações de acordo com seus respectivos tipos de tecnologia: rotineira, ofício, não-rotineira ou engenharia.

Pesquisas em tecnologia de operações foram conduzidas, ao nível individual, por Meissner ${ }^{37}$ e Turner. ${ }^{38}$ Para se operacionalizar o conceito, o primeiro autor desenvolveu o critério de nível de "automação". Fazendo-se isto, uma distinção é primeiramente feita entre dois amplos tipos de operaçōes: operaçōes de conversão e operaçōes de transferência. Em segundo lugar, escalas separadas para ambos os tipos de operações foram construidas de acordo com o grau de controle humano (oposto ao controle de máquina) exercido sobre o ciclo completo de produção. Correlacionando ambás as escalas, Meissner construiu uma matriz de, assim chamadas, "distinções técnicas" na qual se situa uma variedade de casos empíricos. Para Turner e Lawrence, os diversos tipos de operações industriais caracterizaram-se em termos de "complexidade". Esta variável é medida por meio de um índice contendo três componentes maiores, cada um dividido em dois elementos alternativos: $a)$ atividade (variedade e autonomia); $b$ ) interação (requerida e opcional); $c$ ) condições mentais (tempo para aprender o serviço e responsabilidade).
Tentativas teóricas e empíricas no sentido de se operacionalizar o conceito de tecnologia de operações, ao nível do grupo, são um tanto raras. É digno de nota, no entanto, o estudo de Sayles ${ }^{39}$ sobre relações entre as tarefas de um grupo e as açōes defensivas desenvolvidas por este último. Sayles acredita que certas características tecnológicas estão relacionadas às diferenças nas estratégias de comportamento desenvolvidas por grupos de trabalho em contextos de fábrica. Critérios de tecnologia de operaçōes são, neste caso, os de a) diferenciação de tarefas; $b$ ) fluxo de trabalho e dependência; $c$ ) ritmo de máquina; $d$ ) interaçð̃es exigidas.

Ao nível da organização como um todo os critérios utilizados para exemplificar a tecnologia de operações podem ser divididos em três grupos: indicadores econômicos baseados na relação trabalho-capital, medidas qualitativas e/ou quantitativas da própria tecnologia, e taxas de mudança tecnológica. No primeiro grupo, a pesquisa de Blauner ${ }^{40}$ sobre a alienação na indústria é digna de menção. Baseado na análise secundária de múltiplos dados, este autor defende que firmas têxteis, automobilísticas e químicas aparecem ordenadas em tal seqüência conforme o seu grau de mecanização e estandartização dos processos de trabalho. Para confirmar a utilização destes dois critérios, Blauner recorre a um ordenamento das firmas com base em indicadores econômicos tais como investimento de capital requerido por trabalhador de produção e a proporção de custos de pessoal não-produtivo na folha de pagamento total.

Encabeçando o segundo grupo de critérios, aquele da "complexidade técnica" de Woodward é certamente o mais citado na literatura. Este critério classifica as organizações manufatureiras em três categorias básicas, isto é, produção por unidade, produção em grande escala e produção de processo contínuo.

Para alguns, no entanto, a escala de "complexidade técnica" construída por Woodward é conceitualmente enganadora. ${ }^{41}$ Porque, na verdade, as categorias em escala não estão ordenadas em termos de complexidade, mas de acordo com o "número" de unidades de produção. Daí, "complexidade tecnológica" significaria regularidade ou continuidade de produção. Baseado nestas críticas, o grupo Aston prefere expressar o conceito de tecnologia de operaçōes em termos de grau de "integração do fluxo de trabalho". apresentado pelo processo produtivo. Embora complicado, este último critério tem uma vantagem sobre o de Woodward; isto é, baseia-se a priori em quatro subcritérios estatisticamente independentes (ainda que altamente correlatos): rigidez do fluxo de trabalho, interdependência dos-segmentos que compõem o fluxo de trabalho, automaticidade e especificidade das operações de controle de qualidade.

Finalmente, procurando melhorar o raciocínio de Woodward, Harvey ${ }^{42}$ parece adotar ainda uma terceira abordagem em direção à operacionalização da tecnologia de operações. As organizações são agrupadas por este autor numa freqüência que vai desde um ponto de extrema "difusão técnica" para um outro ponto de extrema 
"especificidade técnica", dependendo do número de processos técnicos usados ao se produzir um certo número de produtos durante um período de 10 anos. Assim, Harvey leva em conta a "forma" da tecnologia, sem omitir, como Woodward fez, a quantidade de mudanças ocorridas numa "forma" dada.

\subsection{Conclusões sobre a revisão e a seleção de uma alter- nativa}

O propósito fundamental da última revisão foi o de achar um critério de tecnologia "operacional" ao qual associar características de estrutura organizacional, tais como as mencionadas no começo, numa maneira um tanto sistemática. Hipóteses apropriadas para pesquisa poderiam ser tiradas subseqüentemente de tal modelo teórico.

A revisão em referência, no entanto, mostra que tal objetivo não é fácil de se alcançar.

$\mathrm{Na}$ verdade, não se dispōe de uma só medida de tecnologia relacionada sistematicamente à estrutura organizacional. Conseqüentemente, a procura de regras gerais no assunto deve ser deixada de lado, a favor de alternativa de se prosseguir analiticamente, enquanto se estudam casos individuais.

A última alternativa é dificilmente uma novidade. Woodward 43 foi a primeira a considerá-la seriamente depois de admitir que as diferenças em estrutura e comportamento dentro do grupo de firmas de produção em grande escala podem ser explicadas por diferenças demasiado difíceis de se perceber na sua escala de "complexidade técnica". Para ela, o tipo de classificação utilizado nas firmas do sul de Essex acabou abraçando um número de subvariáveis tecnológicas que podem ser independentes umas das outras, e que têm efeitos separados sobre a variável dependente de estrutura organizacional. Conseqüentemente, ele indica: 44

"Um modo possível de se prosseguir além deste ponto pode ser o de abandonar a idéia de se achar uma medida geral de tecnologia, a qual a estrutura organizacional pudesse ser associada substancialmente, preocupando-se apenas em relacionar isoladamente características técnicas específicas, as diferenças em estrutura organizacional e comportamento."

Assim, é provável que algumas, mas não todas as características da tecnologia sejam refletidas na estrutura e comportamento organizacionais. Como sugerido por Turner, ${ }^{45}$ tais características deveriam ser reconhecidas como "caracterísíicas tecnológicas salientes" sendo possível identificá-las ao nivel de tarefa organizacional.

Resumindo, é difícil de se construir um modelo de pesquisa satisfatório baseando-se na classificação a priori de sistemas tecnológicos, particularmente, se tais sistemas se supõem de alguma forma relacionados à estrutura organizacional. A maneira de se proceder para analisar o relacionamento entre tecnologia e estrutura organizacional, seria, então, a de limitar a atenção apenas às características tecnológicas salientes.

\section{A ESTRATÉGIA DA PESQUISA}

Este estudo apóia o argumento de Woodward comentado ao fim da seção anterior, que considera a associação da estrutura organizacional com características "salientes" da tecnologia. Apesar de que, para pesquisar empiricamente tal associação, talvez fosse suficiente selecionar apenas um só tipo de organização e: a) detectar características "salientes" de seu sistema de produção; $b$ ) delinear um perfil aceitável de sua estrutura organizacional; $c$ ) mais adiante, relacionar as características "salientes" ao perfil organizacional; este estudo compara dois tipos organizacionais, cada um centralizado em torno de um sistema de produção diferente.

A primeira parte desta seção inclui a identificação de dois sistemas diferentes de produção como um passo prévio para se escolher organizações a serem pesquisadas empiricamente. A parte seguinte discute a formulação de hipóteses sobre como é que tais organizações se comparam entre si, quanto a aspectos de estrutura organizacional.

\subsection{O critério de seleção dos sistemas de produção}

Este estudo presta atenção, inicialmente, a dois tipos tecnológicos: produção em massa e produção de processo contínuo. Enquanto que o primeiro destes tipos tecnológicos focaliza-se na manufatura de produtos integrais em quantidades infinitas, o segundo tipo diz respeito à execução de produtos dimensionados medidos pelo seu peso, capacidade e volume.

Os dois tipos tecnológicos referidos têm algumas características em comum, mas ainda não está claro como elés se comparam entre si, em termos de seu relacionamento com a estrutura organizacional. Perrow, ${ }^{46}$ por exemplo, considerou ambos os tipos tecnológicos como sendo iguais em termos de "rotina individual" e, portanto, iguais quanto à estrutura organizacional. Para Woodward, ${ }^{47}$ Fullan ${ }^{48}$ e outros, ao contrário, a produção de processo contínuo situa-se como um tipo tecnológico significativamente diferente da produção em massa. Dessa maneira, espera-se que os caracteres das correspondentes estruturas organizacionais se diferenciem também de um tipo tecnológico para outro.

\subsection{Os sistemas de produção}

Um sistema de produção específico foi selecionado de cada um dos tipos tecnológicos mencionados anteriormente, para efeitos de execução da pesquisa comparativa. Os sistemas selecionados foram os de "produção em massa na linha de montagem" e de "produção de processo contínuo".

O primeiro tipo de sistema de produção é aquele em que os diversos componentes de grandes lotes são progrèssivamente montados através de uma aplicação extrema do princípio de divisão de trabalho, em unidades completa- 
mente terminadas. Uma correia transportadora é usada para acionar o processo de trabalho entre as linhas dos trabalhadores, cada um dos quais executa uma operação dada para cor ıpletar a unidade. $O$ número de lotes é geralmente muito baixo e mudanças eventuais em cada um deles requerem, necessariamente, decisões sobre a modificação do modelo do produto e/ou das próprias máquinas operatrizes. Estas últimas decisões estão além da autoridade normal dos supervisores na linha de produção e/ou da administração do planejamento da produção.

Um sistema de produção de processo contínuo, por sua vez, envolve o controle automático e centralizado de um ciclo integrado de operações. Um lote de produção não é imediatamente distinguível de outro. A manipulação de materiais normalmente fluidos é desenvolvida, em geral, por regulagem automática e controle remoto de unidades de processo. $\mathbf{O}$ trabalhador torna-se mero monitor de um painel de instrumentos através do qual controla o ciclo integrado.

\section{A FORMULAÇÃO DE HIPÓTESES}

Baseado nas revisões anteriores da leitura, bem como em algumas informações adicionais, parece possível formular aqui algumas hipóteses a respeito das diferenças em estrutura de trabalho e estrutura social existentes entre organizações de produção em massa e processo contínuo. Estas hipóteses são construídas sobre dados fragmentados $e$, assim, devem ser consideradas mais como regras orientadoras da pesquisa do que qualquer outra coisa. Todas elas caem dentro de uma proposição geral, isto é, que uma firma localizada num tipo de tecnologia de produção massa-linha possui provavelmente um caráter organizacional mais mecanistico do que uma outra firma comparável que utiliza um tipo de tecnologia de processo continuo.

A classificação de organizações como "mecanísticas" ou "orgânicas" é baseada, de fato, num exame detalhado das suas estruturas sociais e de trabalho e numa comparação de seus respectivos padrões organizacionais. Tais padrões foram especificados por Burns e Stalker ${ }^{49}$ como segue:

"Em sistemas mecanisticos os problemas e trabalhos da firma como um todo dividindo-se em especialidades. Cada individıo desempenha tarefas específicas. Alguém no alto é responsável pela importância destas tarefas. Os métodos, obr gações e poderes associados a cada papel funcional estão definidos. A interação dentro da administração tende a ser vertical. As operações e o comportamento no trajalho são governados por instruções e decisões emitidas jor superiores."

"Sistemas orgânicos são adaptados a condições instáveis; os indivíduos têm que desempenhar duas tarefas especiais à luz do seu conhecimento e das tarefas da firma como um tocio. Os cargos perdem muito de suas definições formais em termos de métodes, deveres e poderes e têm que ser redefinidos continuamente pela interação com outros cargos participando numa mesma tarefa. As interações seguem linhas laterais tanto quanto de comando vertical. Omnisciência não pode mais ser atribuída ao diretor da firma."

Como foi indicado antes, com a ajuda das mais recentes descobertas sobre o assunto, torna-se possível parcelar as duas proposições gerais mencionadas em hipóteses mais específicas. Para manter a distinção formulada no começo, algumas das hipóteses cairão numa dimensão de estrutura de tarefas, outras referir-se-ão à dimensão de estrutura social. Hipóteses no primeiro grupo tratarão com aspectos organizacionais, tais como: $a$ ) o grau de desenvolvimento formal do conceito de linha-staff; b) a intensidade do controle estrutural sobre os membros da organização; $c$ ) o uso de mecanismos impessoais de controle. Hipóteses sobre a estrutura social, por sua vez, relacionar-se-ão com questōes de $d$ ) ideologia administrativa; $e$ ) distribuição de influência intra-organizacional.

\section{Sobre o padrão formal de organização}

De acordo com Woodward na organização linha-staff, as unidades de linha são consideradas totalmente responsáveis por resultados e assim mantêm autoridade sobre certas questões diretamente relacionadas à consecução desses resultados. Carecendo de tal grau de responsabilidade, as unidades de staff são supostamente responsáveis apenas pela assistência às unidades de linha, quanto à realização das suas tarefas. Desta maneira, a autoridade é exercida pelas unidades staff exclusivamente dentro do seu contexto interno.

Considerando esta última definiçāo, Woodward relata que uma bem demarcada distinção entre os papéis das unidades de linha e de staff ocorre nas categorias intermediárias da sua escala de "complexidade tecnológica", isto é, no caso das firmas de produção em massa. Nas organizações de processo contínuo, ao contrário, não haverá tal tipo de distinção.

\section{Hipótese I}

"Um padrão organizacional do tipo linha-staff ver-se-á mais estritamente reforçado numa organização massa-linha do que numa organização comparável de processo contínuo."

\section{Sobre o controle estrutural}

É comumente aceito que uma primeira compreensão de uma organização pode ser obtida simplesmente através da observação de sua estrutura formal. Não muitos pesquisadores, no entanto, têm sido bem sucedidos ao tentar operacionalizar esta especulação. $O$ trabalho de Woodward, para se começar, demonstra a existência de uma relação entre a "complexidade" da tecnologia e certas 
medidas de configuração de estrutura, como, por exemplo, a amplitude de controle dos diferentes supervisores. Mas uma coisa é apontar tal relacionamento e outra é especificar até que ponto certos caracteres de configuração resultem verdadeiramente num maior ou menor controle, sendo exercitado pela estrutura sobre os membros da organização. A respeito disto, as observaçð̃es de Woodward são confusas. De fato, Woodward declara que quanto mais complexa a tecnologia, maior o número de níveis hierárquicos e mais restritas às amplitudes de controle dos níveis de supervisão, médios e de primeira linha. Assim, apenas admitindo que o controle estrutural se torna mais forte numa estrutura organizacional configurada longa e restritamente do que nunca mais estendida, é que um relacionamento direto entre o conceito de controle estrutural e a "complexidade" da tecnologia pode chegar a ser sugerido.

\section{Hipótese II}

"O controle estrutural será menor numa organização massa-linha do que numa outra organização comparável de processo continuo."

\section{Sobre mecanismos impessoais de controle}

Desde Weber até recentemente, o controle nas organizaçóes tinha sido considerado, tanto pelos estudantes de administração de empresas como pelos próprios gerentes, simplesmente como resultante da distribuição e legitimação da autoridade formal ao longo de toda a pirâmide hierárquica. Dentro deste contexto, elementos normativos foram considerados como mecanismos impessoais de controle não necessariamente relacionados à tecnologia.

Pode ter sido Joan Woodward ${ }^{50}$ e sua equipe de pesquisadores do Imperial College quem primeiro citou os mecanismos impessoais de controle dentro de um contexto mais amplo. Para eles, os complexos processos assotriais modernas não podem ser adequadamente explicados, em termos de uma simples pirâmide hierárquica. Isto acontece, eles raciocinam, porque devido a um crescimento do tamanho organizacional e da própria complexidade tecnológica, a possibilidade dos gerentes de linha exercerem controle hierárquico tende a decrescer. Mais precisamente, eles "não podem mais possuir um conhecimento intimo dos diversos processos especializados e complexos que são intrínsecos à fabricação".

"Para evitar o perigo de perder o controle do trabalho de produção a gerência incorpora na organização processos impessoais de controle que influenciam e regulam o comportamento daqueles que ela emprega."

Com respeito à natureza desses mecanismos de controle impessoal, no entanto, Woodward considera-os todos como sendo relativamente associados com a tecnologia. Eles podem ser assim "administrativos", contendo tais coisas como programas complexos para o planejamento da

produção, mecanismos de medida e/ou sistemas de controle de custos, ou "mecânicos" como no : ontrole automático de máquina-ferramentas ou de urna fábrica de processo contínuo de produção.

Visto o anterior, uma hipótese apropriada sobre a questão seria a seguinte:

\section{Hipótese III}

"Mecanismos impessoais de controle de natureza administrativa serão mais desenvolvidos (isto é, numerosos, difundidos e detalhados) numa organização massa-linha do que numa outra organização comparável de processo continuo."

\section{Sobre ideologia administrativa}

Perrow ${ }^{51}$ discutiu que metas operacionais estáveis, nãoinovadoras e essencialmente quantitativas são geralmente adotadas por organizações cuja tecnologia enfatiza a rotina individual. Metas de um tipo oposto são conseqüientemente abraçadas por organizações centradas em torno de tecnologia baseada na livre iniciativa individual. Como indicado anteriormente, diferenças quanto a metas entre organizações rotineiras e não-rotineiras foram recentemente confirmadas por Magnusen. ${ }^{52}$ Se as metas organizacionais são tomadas como reflexões da ideologia administrativa, pode-se desta forma concluir, inicialmente, que esta ideologia parecia ser mais conservadora numa organização massa-linha do que numa organização de processo contínuo.

\section{Hipótese IV}

"A ideologia administrativa será mais conservadora (isto é, estável, não-inovadora, consciente dos aspectos formais da organização e pouco orientada para a consideração de aspectos interpessoais) numa organização massa-linha do que numa outra organização comparável de processo contínuo."

\section{Sobre a distribuição de influência organizacional}

A questão de distribuição interna de influência em organizações centradas em torno de tecnologias diferentes tem sido pesquisada empiricamente por Lawrence e Lorsch, 53 Woodward, 54 Perrow ${ }^{55}$ e indiretamente por Kavcic e outros. 56

Os primeiros autores, por exemplo, demonstraram que a soma total da influência hierárquica é mais baixa e menos desigualmente distribuída entre níveis hierárquicos em indústrias de fabricação de recipientes (produção em massa) do que em firmas de fabricação de plásticos (produção de processo contínuo). Além disso, os autores acrescentam que ambas as firmas diferem em termos de distribuição de influência funcional, baseando-se numa 
comparação entre as funçðes básicas de vendas, produção e pesquisa e desenvolvimento. Uma descoberta quase idêntica já tinha sido adiantada por Woodward anos antes, após a conclu ão do estudo no Essex.

Kavcic e associados relatam variaçðes significativas entre "curvas de controle" em fábricas iugoslavas dedicadas à fabricação de borracha, confecção de sapatos e laminação de madeira. Fábricas de borracha (produção de processo contínuo) mostraram uma quantidade de controle maior e mais equitativamente distribuída do que as outras.

Perrow, baseando-se numa amostra de 12 firmas independentes escolhidas de duas áreas industriais nos EUA, falha em provar a suposição de que a influência de vendas seria maior em firmas que usam uma tecnologia rotineira. Aparentemente, variáveis de liderança e a própria história organizacional, aspectos estes que não foram medidos, desempenharam também um papel importante na distribuição de influência. Alguns dados, no entanto, indicaram sugestivamente que firmas que apresentavam uma ligação "inapropriada" entre a sua tecnologia e o nível de influência de vendas procuraram reorientar este relacionamento para fazê-lo apropriado à teoria.

\section{Hipótese $V$}

A soma total de influência na organização será mais baixa e desigualmente distribuída entre níveis hierárquicos e funções numa organização de massa-linha do que numa outra organização comparável do processo-contínuo.

\section{COMENT'ÄRIOS FINAIS}

Obviamente, este artigo não é (nem pretendia ser) conclusivo. De fato, as cinco hipóteses mencionadas foram testadas através de um caso-estudo de ordem comparativa que incluiu empresas automobilísticas, petroquímicas e farmacêuticas na Grande São Paulo. Os resultados obtidos nesse caso-estudo s:rão matéria de um outro artigo ainda em fase de preparação. Como indicado no começo, a intenção aqui era apenas de detalhar a metodologia seguida na formulação de uma pesquisa sobre aspectos básicos de comportamento organizacional. Isto foi logrado, primeiro, através de uma rigorosa revisão da literatura existente sobre o tema da pesquisa. Assim, pelo menos, houve possibilidade de diferenciar o que é conhecido daquilo meramente presurnível. Segundo, com base na classificação anterior, foi também possível aprimorar os conceitos utilizados (variáveis dependentes e independentes) antes de, finalmente, fcrmular hipóteses específicas de pesquisa.

A esta al ura, no entanto, o leitor provavelmente perguntar-se-á sobre a utilidade prática de tanto esforço acadêmico. Coño a ciência do comportamento organizacional é muits nova, esta interrogação merece ser tomada em consideração.

Em primeiro lugar, a lógica que sustenta o artigo todo é que as orgatizações, estruturalmente falando, são signifi- cativamente diferentes. Para o empresário schumpeteriano, isto pode ser óbvio, considerando que a sua razão de ser é mesmo a inovação. Mas, tal empresário já não é tão comum como antigamente, havendo sido substitufdo pelo chamado "homem organizacional". Embora este último possua uma educação "científica" em administração de empresas baseada essencialmente em princípios e dogmas de caráter relativamente universal. Em conseqüência, ele provavelmente, acredita que as comunicaçōes que respeitam o princípio hierárquico são sempre boas, que um gerente supervisionando mais de uma dúzia de subordinados não pode ser efíciente, que todo "caos administrativo" é solucionado por meio de um esforço normativo, e assim por diante. Se as hipóteses formuladas neste artigo são corretas, ter-se-á demonstrado que tal visão está errada.

Em segundo lugar, o artigo entrega elementos de análise (especificação de conceitos-chaves, relacionamentos entre variáveis, etc.), que podem ser muito valiosos tanto para o gerente que luta por melhor entender seu ambiente de trabalho, quanto para o consultor que é chamado a diagnosticar problemas organizacionais com vistas a uma possivel introdução de mudança. Entender a maneira pela qual as incertezas ambientais fazem com que um certo grupo funcional (por exemplo: vendas) se torne mais influente dentro de um tipo de organização do que em outro pode levar a uma explicação da motivação e/ou do desempenho desse grupo (ou daqueles outros grupos menos influentes). A teoria das organizações não pode mais continuar sendo um pacote de áridas formulaçöes acadêmicas. $O$ seu imediato desafio consiste em começar a entregar instrumentos analíticos, úteis para o homem de ação, sejam eles métodos de análise ou descobertas propriamente ditas.

Em terceiro lugar, 0 artigo tem um valor didático para os alunos que freqüentam os diversos cursos de pósgraduação em administração de empresas existentes no pais, os quais confrontam a inconfortável tarefa de basear a sua tese de grau numa pesquisa empírica original. Infelizmente, não há publicações relativas a pesquisas sobre comportamento organizacional no Brasil. Esta pesquisa, então, pode formar parte da base, sobre a qual o pesquisador possa construir uma ciência do comportamento organizacional que, se ensinada nas maiores escolas de administração de empresas nacionais, venha a incorporar gradualmente elementos peculiares à realidade brasileira.

1 Baseado em Whyte, W. F. The social structure of the restaurant. The American Journal of Sociology, v. 54, p. 302-10, Jan. 1949.

2 Thompson, J. D. \& Bates, F. L. Technology, organization and administration. Administrative Science Quarterly, v. 3, p. 325-43, Dec. 1957.

3 Perrow, Charles. Organizational analysis: a sociological view. Belmont, California, Wadsworth Publishing, 1970. p. 100. 
4 Magnusen, Karl. Technology and organizational differentiation: a field study of manufacturing corporations. Unpublished doctoral dissertation, University of Wisconsin, Madison, 1970.

5 Burns, Tom \& Stalker, G. M. The management of innovation. London, Tavistock Publications, 1961.

6 Fouraker, Lawrence E. Unpublished manuscript Apud: Lawrence, P. R. \& Lorsch, J. W. Organization and environment. New York, R. D. Irwin, 1969.

7 Woodward, Joan. Industrial organization: theory and practice. London, Oxford University Press, 1965.

8 Fullan, Michael Industrial technology and worker integration in the organization. American Sociological Review, v. 35, p. 1028-39, Dec. 1970.

9 Mohor, L. B. Organizational technology and organizational structure. Administrative Science Quarterly, v. 15, p. 26-9, Oct. 1970.

10 Samuels, Itzka \& Mannheim, B. A multidimensional approach toward a typology of bureaucracy. Administrative Science Quarterly, v. 15, p. 26-9, Oct. 1970.

11 Hickson, D. J. et alii. Operations technology and the context of organization structures: an empirical reappraisal. Administrative Science Quarterly, v. 14, p. 378-97, Sep. 1969.

12 Ibid. p. 395.

13 Warner, Lloyd W. \& Low, J. O. The social system of the modern factory. The strike: a social analysis. New Haven, Yale University Press, 1947.

14 Mouzelis, Nicos P. Organization and bureaucracy: an analysis of modern theories. Chicago, Itl. Aldine Publishing, 1968. p. 104.

15 Chapple, Elliot. Applied anthropology in industry. In: Kroeber, A. L. ed. Anthropology today. Glencoe, 111., The Free Press, 1953.

16 Arensberg, Conrad \& Tooall, George. Plant sociology: real discoveries and new problems. In: Komarovsky, M. ed. Common frontiers of the social sciences. Glencoe, I11., The Free Press, 1957.

17 Whyte, William F. An interaction approach to the theory of organization. In: Haire, M. ed. Modern organization theory. New .York, John Wiley and Sons, 1959.

18 Sayles, Leonard R. Behavior of industrial work groups: prediction and control. New York, John Wiley and Sons, 1958.

19 Thurley, Keith E. \& Hamblin, A. C. The supervisor and his job. 1963. Series of Problems of Progress an Industry, n. 13.

20 Dubin, Robert. Supervision and productivity: empirical findings and theoretical considerations. In: Dubin, R. et alii Leadership and productivity. San Francisco, Chandler Publishing, 1965.

21 Burack, Elmer. Industrial management in advanced production systems: some theoretical concepts and preliminary findings. American Sociological Review, v. 12, p. 497-500, Dec. 1967.

22 Fiedler, Fred E. Engineer the job to fit the manager. Harvard . Business Review. v. 43, p. 115-22, Oct. 1965.

23 Trist, Emery L. \& Bamforth, K. W. Selection from social and psychological consequences of the long-hall method of coal getting Human Relations, v. 4, p. 6-38, Jan. 1951.

24 Gouldnet, Alvin W. Parterns of industrial democracy. New York, The Free Press, 1954.

25 Woodward. Industrial arganization: theory and practice. London, Oxford University Press, 1965. p. 83.

26 Lawrence, Paul R. \& Lorsch, Jay W. Organization and environment. New York, R. D. Irwin, 1969.

27 Magnusen. op. cit. p. 27.
28 Blauner, Robert. Alienation and freedom: the factory worker and his industry. Chicago, University of Chicago $P$ ess, 1964.

29 Perrow, Charles. A framework for the comparative analysis of organizations. American Sociological Review, v. 32, p. 191-208, Apr. 1967.

30 Fullan. Industrial technology ... op. cit.

31 Hickson, D. J. et alii. Operations technology and organization structure: an empirical reappraisal. Administrative Science Quarterly, v. 14, p. 378-97, Sep. 1969.

32 Pugh, D. S. et alii. The context of organization structure. Administrative Science Quarterly, v. 14, p. 91-113, Mar. 1969.

33 Perrow. A framework ... op. cit. p. 195.

34 Thompson, James D. Organizations in action. New York, McGraw-Hill Book, 1967.

35 March, James G. \& Simon, Herbert A. Organizations. New York. John Wiley and Sons, 1958.

36 Perrow. A framework ... op. cit.

37 Meissner, Martin. Technology and the worker. New York, Chandler Publishing, 1969.

38 Turner, Arthur N. \& Lawrence, Paul R. Industrial jobs and workers: an investigation of responses to task attributes. Boston, Harvard University Press, 1965.

39 Sayles. Behavior of industrial work groups . . . op. cit.

40 Blauner. Alienation and freedom ... op. cit.

41 Hickson et alii. Operations technology ... op. cit. p. 391.

42 Harvey, Edward. Technology and organization structure. American Sociological Review, v. 33, p. 251-7, Jan. 1968.

43 Woodward, Joan. Industrial organization: behavior and control. London, Oxford University Press, 1970.

44 Ibid. p. 13.

45 Turner, Bernard A. Unpublished research paper on technological salience. Imperial College, England, 1970.

46 Perrow, Charles. Organizational analysis: $A$ sociological view. Belmont, California, Wadsworth Publishing, 1970. p. 85.

47 Woodward, Joan. Industrial organization: theory and practice. London, Oxford University Press, 1965.

48 Fullan, Michael. Industrial technology and worker integration in organization. American Sociological Review, v. 35, p. 1028-39, Dec. 1970.

49 Burns, Tom \& Stalker, G. M. The management of innovation. London. Tavistock Publications, 1961. As summarized in Paul R. Lawrence and Jay W. Lorsch, Organization and Environment. New York, R. D. Irwin, 1969. p. 188.

so Woodward. Industrial organization: behavior and control. op. cit. p. 44.

51 Perrow. Organizational andysis ... op. cit. p. 97.

52 Magnusen, Karl. Technology and organizational differentiation: a field study of manufacturing corporations. Unpublished doctoral dissertation, University of Wisconsin, Madison, 1970.

53 Lawrence, Paul R. \& Lorsch, Jay W. Organization and environment. New York, R. D. Irwin, 1969.

54 Woodward. Industrial organization: theory and practice. op. cit. p. 125.

55 Perrow, Charles. Departmental power and perspective in industrial firms. In: Zald, M. N. ed. Power in organizations. Nashville, Tenn. Vanderbilt University Press, 1970.

56 Kavcic, Boris et alii. Control, participation and effectiveness in four Jugoslav industrial organizations. Administrative Science Quarterly, v. 16, p. 74-83, Mar. 1971. 